\title{
Thyroid autoimmunity in relation to islet autoantibodies and $H L A-D Q$ genotype in newly diagnosed type 1 diabetes in children and adolescents
}

\author{
B. Jonsdottir • C. Andersson • A. Carlsson • A. Delli • G. Forsander • J. Ludvigsson • \\ C. Marcus • U. Samuelsson • E. Örtqvist • Å. Lernmark • S.-A. Ivarsson • \\ H. Elding Larsson • for the Better Diabetes Diagnosis (BDD) study group
}

Received: 20 December 2012 / Accepted: 22 April 2013 /Published online: 12 May 2013

(C) Springer-Verlag Berlin Heidelberg 2013

\begin{abstract}
Aims/hypothesis The aim of this work was to investigate, in children newly diagnosed with type 1 diabetes: (1) the prevalence of autoantibodies against thyroid peroxidase (TPOAb) and thyroglobulin (TGAb); and (2) the association between TPOAb, TGAb or both, with either islet autoantibodies or $H L A-D Q$ genes.

Methods Blood samples from 2,433 children newly diagnosed with type 1 diabetes were analysed for TPOAb and $\mathrm{TGAb}$ in addition to autoantibodies against arginine zinc transporter 8 (ZnT8RA), tryptophan zinc transporter 8 (ZnT8WA), glutamine zinc transporter 8 (ZnT8QA),
\end{abstract}

Members of the BDD study group are listed in the Appendix.

B. Jonsdottir $(\bowtie) \cdot$ C. Andersson $\cdot$ A. Delli $\cdot \AA$. Lernmark $\cdot$

S.-A. Ivarsson $\cdot$ H. E. Larsson

Lund University/CRC, Department of Clinical Sciences, Skåne

University Hospital SUS, Jan Waldenströms gata 35,

20502 Malmö, Sweden

e-mail: berglind.jonsdottir@gmail.com

\section{A. Carlsson}

Department of Pediatrics, Lund University, Skåne University

Hospital, Lund, Sweden

G. Forsander

Department of Clinical Neurosciences, Karolinska Institute,

Stockholm, Sweden

\section{J. Ludvigsson · U. Samuelsson}

Division of Pediatrics, Department of Clinical and Experimental

Medicine, Linköping University Hospital, Linköping, Sweden

\section{Marcus}

Division of Pediatrics, Department of Clinical Science,

Intervention and Technology Karolinska Institute, Stockholm,

Sweden

E. Örtqvist

Pediatric Endocrinology Unit, Department of Woman and Child

Health, Karolinska Institute, Stockholm, Sweden glutamic acid decarboxylase (GADA), insulin (IAA), insulinoma-associated protein-2 (IA-2A), $H L A-D Q A-B 1$ genotypes, thyroid-stimulating hormone (TSH) and free thyroxine (T4).

Results At type 1 diabetes diagnosis, $12 \%$ of the children had thyroid autoantibodies $(60 \%$ were girls; $p<0.0001)$. GADA was positively associated with TPOAb $(p<0.001)$ and with TGAb $(p<0.001)$. In addition, ZnT8A was associated with both TPOAb $(p=0.039)$ and TGAb $(p=0.015)$. $D Q B 1 * 05: 01$ in any genotype was negatively associated with TPOAb (OR $0.55,95 \%$ CI $0.37,0.83, p$ value corrected for multiple comparisons $\left.\left(p_{\mathrm{c}}\right)=0.012\right)$ and possibly with TGAb (OR $0.55,95 \%$ CI $0.35,0.87, p_{\mathrm{c}}=0.07$ ). Thyroid autoimmunity in children newly diagnosed with type 1 diabetes was rarely $(0.45 \%)$ associated with onset of clinical thyroid disease based on TSH and free T4. Conclusions/interpretation GADA and ZnT8A increased the risk for thyroid autoimmunity at the time of clinical diagnosis of type 1 diabetes, while $H L A-D Q B 1 * 05: 01$ reduced the risk. However, the associations between thyroid autoimmunity and $H L A-D Q$ genotype were weak and did not fully explain the co-occurrence of islet and thyroid autoimmunity.

Keywords Autoimmune thyroid diseases $\cdot$ Diabetes mellitus · GAD65 autoantibodies · HLA genotype - IA-2 autoantibodies $\cdot$ Insulin autoantibodies $\cdot$ Thyroglobulin antibodies Thyroid peroxidase antibodies · Type 1 diabetes . ZnT8 autoantibodies

$\begin{array}{ll}\text { Abbreviations } \\ \text { AITD } & \text { Autoimmune thyroid diseases } \\ \text { BDD } & \text { Better Diagnosis of Diabetes } \\ \text { DASP } & \text { Diabetes Autoantibody Standardization } \\ & \begin{array}{l}\text { Program } \\ \text { fT4 }\end{array}\end{array}$

Abbreviations

Autoimmune thyroid diseases

Better Diagnosis of Diabetes

fT4 Free thyroxine 


$\begin{array}{ll}\text { GADA } & \text { Autoantibodies to glutamic acid decarboxylase } \\ \text { IAA } & \text { Insulin autoantibodies } \\ \text { IA-2A } & \text { Insulinoma-associated protein 2 autoantibodies } \\ p_{\mathrm{c}} & p \text { value corrected for multiple comparisons } \\ \text { T4 } & \text { Thyroxine } \\ \text { TG } & \text { Thyroglobulin } \\ \text { TGAb } & \text { TG autoantibodies } \\ \text { TPO } & \text { Thyroid peroxidase } \\ \text { TPOAb } & \text { TPO autoantibodies } \\ \text { TSH } & \text { Thyroid-stimulating hormone } \\ \text { ZnT8RA } & \text { Arginine } 325 \text { zinc transporter } 8 \text { autoantibody } \\ \text { ZnT8WA } & \text { Tryptophan 325 zinc transporter } 8 \text { autoantibody } \\ \text { ZnT8QA } & \text { Glutamine } 325 \text { zinc transporter } 8 \text { autoantibody } \\ \text { ZnT8A } & \text { Zinc transporter } 8 \text { autoantibody to either one or } \\ & \text { all three amino acid variants at position 325 }\end{array}$

\section{Introduction}

Type 1 diabetes mellitus and autoimmune thyroid diseases (AITD) are common autoimmune endocrine disorders [1]. Type 1 diabetes develops through a complex interaction of genetic and environmental factors and is characterised by immunemediated destruction of the pancreatic islet beta cells [2]. Individuals with type 1 diabetes often develop other autoimmune diseases, of which AITD is the most frequent [1]. As childhood clinical hypothyroidism has an impact on growth and intellectual development as well as on glucose control in type 1 diabetes patients, screening for AITD may be important at the clinical diagnosis of type 1 diabetes and during follow-up.

The pathogenesis of AITD involves both humoral and cellular immune responses against the thyroid autoantigens thyroid peroxidase (TPO) and thyroglobulin (TG). These autoantibodies are produced in parallel to infiltration of $\mathrm{T}$ and B lymphocytes in the thyroid gland [3].

Autoantibodies to glutamic acid decarboxylase 65 (GADA), insulinoma-associated protein 2 (IA-2A) and insulin (IAA) are predictive and diagnostic markers of type 1 diabetes $[4,5]$. Recently, autoantibodies to the zinc transporter 8 (ZnT8A) have been shown to contribute to the diagnostic sensitivity of diabetes [6-8]. Interestingly enough, ZnT8 is not only expressed in beta cells [9] but also in the cubical cells lining the thyroid follicle [10]. SLC30A8 encodes three amino acid variants of ZnT8A to amino acids at position 325 (arginine [ZnT8RA], tryptophan [ZnT8QA] or glutamine [ZnT8QA]), having possible consequences for the association with $H L A-D Q$ genotype [8].

Both type 1 diabetes and AITD have a complex genetic background. The major genetic susceptibility of type 1 diabetes has been mapped to the HLA region on the short arm of chromosome 6, particularly the class II $D Q$ and $D R$ genes. $D Q A 1 * 03: 01-B 1 * 03: 02$ (DQ8), $D Q A 1 * 05: 01$ $B 1 * 02: 01(D Q 2)$ or both haplotypes, confer the highest risk for type 1 diabetes [11]. It is of interest that GADA was associated with $D Q 2$ and IAA and IA-2A with $D Q 8$, while $D Q 2$ was associated with a decreased risk for IA-2A [12]. Autoantibodies against TPO (TPOAb) and TG (TGAb) were also associated with $H L A-D Q$ genotype [13, 14], although their relationships with specific $H L A-D Q$ haplotypes were less obvious and would need further clarification in larger studies.

The paucity of population-based investigations of TPOAb and TGAb in incident children and adolescents newly diagnosed with type 1 diabetes would require large investigations such as the Better Diabetes Diagnosis (BDD) study in Sweden [15]. Since it is important to find AITD in children and adolescents, investigations of genetic and immunological associations may be needed to improve the diagnostic sensitivity and specificity for thyroid autoimmunity and clinical thyroid disease in patients with type 1 diabetes.

The aim of this study was to investigate Swedish patients with type 1 diabetes consecutively diagnosed at up to 18 years of age between May 2005 and October 2009 for: (1) the prevalence of TPOAb and TGAb; (2) the association between TPOAb or TGAb and islet autoantibodies; (3) the association between TPOAb or TGAb and $H L A-D Q$ genotype; and (4) the relationship to thyroid-stimulating hormone (TSH) and free thyroxine (T4). We hypothesised that: (1) TPOAb and TGAb in children at the clinical onset of type 1 diabetes would be associated with autoantibodies to ZnT8 because they are also expressed in the thyroid; and (2) the large number of individuals studied would allow us to detect associations between $H L A-D Q$ genotype and thyroid autoantibodies.

\section{Methods}

Study population In Sweden, with 9.4 million inhabitants, all children and adolescents with type 1 diabetes are diagnosed and treated in 43 paediatric clinics. BDD is a prospective study including almost all children under the age of 18 with newly diagnosed diabetes in Sweden [15]. Patients with type 2 diabetes, MODY and neonatal and secondary diabetes were excluded. Blood samples were collected between May 2005 and October 2009 at onset of type 1 diabetes $(n=2,670)$ and analysed for $H L A-D Q$ genotype and GADA, ZnT8RWQA, IAA and IA-2A as well as TPOAb, TGAb, TSH and free T4. After exclusion of 237 children with missing data, 2,433 remained (Fig. 1$) ; 56 \%$ boys $(n=1,390)$ and $44 \%$ girls $(n=1,073)$, with a median age of 10.3 years (range $0.7-17.9)$.

Autoantibodies to TPO and TG The analysis of TPOAb (kit No. L2KTO2) and TGAb (kit No. L2KTG2) were performed on serum samples on the Immulite 2000 analyzer according to the manufacturer's instructions (Siemens Healthcare Diagnostics, Deerfield, IL, USA). 
Fig. 1 Flow chart of the distribution of thyroid autoantibodies in the 2,670 patients newly diagnosed with type 1 diabetes

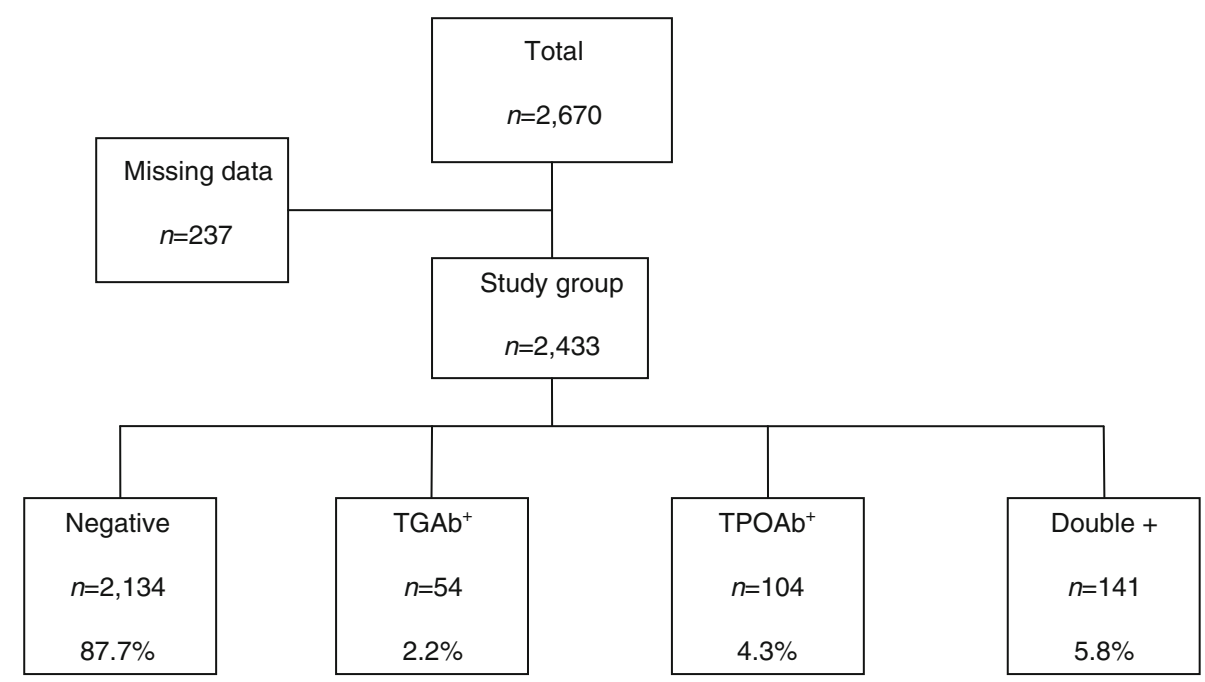

Autoantibodies to zinc T8 transporter variants The radiobinding assay for all three variants, ZnT8R, ZnT8W and ZnT8Q, were performed as previously described [8]. The results were expressed in arbitrary units derived from in-house positive and negative standard samples. Intra-assay CV for the ZnT8RA was 6\%, ZnT8WA 5\% and ZnT8QA 4\%. Inter-assay CV for ZnT8RA was 7\%, ZnT8WA 8\% and ZnT8QA 10\%. Our laboratory has been validated in Diabetes Autoantibody Standardization Program (DASP) 2011 with $50 \%$ study sensitivity and $100 \%$ study specificity for ZnT8RA, 46\% study sensitivity and 100\% study specificity for ZnT8WA and 38\% study sensitivity and 100\% study specificity for ZnT8QA [16]. Cut-off values were ZnT8RA $\geq 75, \mathrm{ZnT} 8 \mathrm{WA} \geq 75$ and $\mathrm{ZnT} 8 \mathrm{QA} \geq 100 \mathrm{U} / \mathrm{ml}$.

Autoantibodies to GAD65 and IA-2 The radiobinding assays for GADA and IA-2A were carried out as detailed elsewhere [15]. GADA and IA-2A levels were expressed as $\mathrm{U} / \mathrm{ml}$ derived from the WHO standard 97/550 [17]. Samples were considered positive if GADA levels were above $50 \mathrm{U} / \mathrm{ml}$ and IA-2A levels above $10 \mathrm{U} / \mathrm{ml}$. The intra-assay $\mathrm{CV}$ for duplicates in the GAD65A assay was 7\% and in the IA-2A, 11\%. In the DASP 2009, GAD65A showed workshop sensitivity of $68 \%$ and specificity of $99 \%$ and IA-2A sensitivity of $60 \%$ and specificity of $99 \%$ [18].

Autoantibodies to insulin The radiobinding assay for IAA was carried out as described [19]. The results were expressed in arbitrary units derived from in-house positive and negative standard samples. Samples were considered positive if IAA levels were above 1 RU. Intra-assay CV was $6 \%$ and inter-assay CV 13\%. Our laboratory has been validated in DASP 2010 with 26\% workshop sensitivity and $100 \%$ workshop specificity.

$H L A$ genotyping $H L A-D Q B 1$ and -DQA1 alleles were typed by sequence-specific oligonucleotide probes on a dried blood spot used directly for PCR amplification of $D Q A 1$ and $D Q B 1$ alleles using a DELFIA Hybridization assay (Perkin Elmer, Boston, MA, USA) as described [20]. The first set of probes defines the presence of $H L A-D Q B 1^{*} 02$, 03:02, 03:01, 06:02, 06:03 and 06:04 (DQ6.4). The second set of probes defines the presence of additional $D Q B 1$ alleles. $H L A-D Q A 1$ probes define the $D Q A 1 * 02: 01,03: 01$ and 05:01 alleles. We compared patient HLA frequencies with 2,000 newborn children in the Diabetes Prediction in Skåne (DiPiS) study [21, 22].

Serum TSH and free T4 The analysis of TSH and free T4 (fT4) was performed on serum samples using the Immulite 2000 analyser according to the manufacturer's instructions (Siemens Healthcare Diagnostics). As mild transient TSH derangements are common at clinical onset of type 1 diabetes, the following values were used for hypothyroid disease: TSH $>8 \mathrm{mU} / 1$ and $\mathrm{fT} 4<12 \mathrm{pmol} / 1$ and for hyperthyroid disease: TSH $<0.01 \mathrm{mU} / 1$ and $\mathrm{fT} 4>22 \mathrm{pmol} / \mathrm{l}$.

Statistical methods Statistical analyses were performed using SPSS statistical software (version 18.0; SPSS, Chicago, IL, USA). The Mann-Whitney test was used to compare differences between two independent groups. Differences in proportions between groups were tested using the $\chi^{2}$ test or Fisher's exact test when appropriate and ORs with 95\% CI were calculated. All $p$ values for the HLA-DQ gene associations were corrected for multiple comparisons $\left(p_{\mathrm{c}}\right) . p<0.05$ was considered significant.

\section{Results}

TPO and TG autoantibodies in relation to age and sex At the time of diagnosis, a total of $12.3 \%(299 / 2,433)$ of the patients were positive for either TPOAb $(10.1 \% ; 245 / 2,433)$, TGAb $(8 \% ; 195 / 2,433)$ or both $(5.8 \% ; 141 / 2,433)$. There 
were $44 \%$ girls $(1,073 / 2,433)$ among the 2,433 patients but among the TPOAb-positive patients, $60.8 \%$ were girls $(p<$ 0.001). Among the patients with TGAb, 57.9\% (113/195) were girls $(p<0.001)$. Among patients positive for both TPOAb and TGAb, $62 \%(87 / 141)$ were girls $(p<0.001)$. The girl-to-boy ratio was $1.65: 1$ in TPOAb-positive patients, 1.72:1 in TGAb-positive patients and 1.68:1 in patients positive for TPOAb, TGAb or both.

Children negative for TPOAb and TGAb had a median age of 9.9 years (range 0.7-17.9). Compared with the thyroid-autoantibody-negative children, those positive for both TPOAb (median age 12.2 years; range 1.4-17.9; $p<$ 0.0005 ) and TGAb (median age 12.1 years; range 2.2-17.9; $p<0.0005)$ were older. The children positive for both $\mathrm{TPOAb}$ and TGAb were also older (median age 12.4 years; range $2.5-17.9 ; p<0.0005)$.

Association between TPO or TG autoantibodies and islet autoantibodies TPOAb were found to be associated with GADA $(p<0.0001)$ (Table 1). In addition, TPOAb were associated with ZnT8A as one group $(p=0.039)$ (Table 1). When analysing the three individual ZnT8RAs it was found that this association was partly explained by a significant association between TPOAb and ZnT8RA $(p=0.036)$ (Table 1), while there was no significant association with either ZnT8WA $(p=0.48)$ or ZnT8QA $(p=0.38)$. In contrast, TPOAb were negatively associated with IAA $(p=0.030)$ (Table 1$)$.

TGAb were also positively associated with GADA $(p<0.0001)$ (Table 1$)$ as well as with $\mathrm{ZnT} 8 \mathrm{~A}$ as one group $(p=0.015)$ but no association was found between TGAb and any of the individual variants of ZnT8A or IAA. Neither TGAb nor TPOAb were associated with IA-2A.

TPOAb and TGAb in association with HLA TGAb but not TPOAb showed a possible association with genotypes containing $D Q A 1 * 05: 01-B 1^{*} 02: 01 \quad\left(p=0.014 ; p_{\mathrm{c}}=0.098\right)$ (Table 2). In contrast, a negative association was found between TPOAb and genotypes containing $D Q A 1 * 01: 01$ $B 1^{*} 05: 01 \quad\left(p=0.004 ; p_{\mathrm{c}}=0.012\right)$. The $D Q 8 / 5.1$ genotype also showed a weak negative association with TPOAb $(p=$ $\left.0.019 ; p_{\mathrm{c}}=0.057\right)$ (Table 2). TGAb also tended to be negatively associated with genotypes containing the $D Q 5.1$ haplotype $\left(p=0.01 ; p_{\mathrm{c}}=0.07\right)$, in addition to the $D Q 8 / 5.1$ genotype $\left(p=0.0095 ; p_{\mathrm{c}}=0.067\right)$ (Table 2$)$.

TPOAb, TGAb or both, as an indication of thyroid autoimmunity, showed a negative association with genotypes containing $D Q A 1 * 01: 01-B 1 * 05: 01\left(p=0.002 ; p_{\mathrm{c}}=\right.$ $0.014)$ and a possible weak association with the genotype $D Q 8 / 5.1\left(p=0.0085 ; p_{\mathrm{c}}=0.060\right)$.

Association of TSH and fT4 with thyroid autoantibodies Patients with TPOAb, TGAb or both, were more likely to have clinical thyroid disease at diagnosis of type 1 diabetes compared with thyroid-autoantibody-negative patients $(p<$ 0.001) (Table 3). The data in Table 3 suggest that of the patients studied, there may be six with hypothyroid disease and five with hyperthyroid disease $(0.45 \%$ of the entire study group).

\section{Discussion}

In this study of 2,433 children and adolescents with type 1 diabetes, we found a prevalence of $12.3 \%$ TPOAb, TGAb or both, already at the time of diagnosis of the diabetes. While the association between TPOAb or TGAb and GADA has been described previously [1,23], it was a novel finding that both types of thyroid autoantibodies were positively associated with ZnT8A. The negative association between TPOAb and IAA was also a novel observation. Our large

Table 1 Association between islet autoantibodies and autoantibodies against either TPO or TG

\begin{tabular}{|c|c|c|c|c|c|c|}
\hline Islet autoantibody & Thyroid autoantibody & Islet autoantibody positive & Islet autoantibody negative & OR & $95 \% \mathrm{CI}$ & $p$ value \\
\hline GADA & $\begin{array}{l}\text { TPOAb + } \\
\text { TPOAb - }\end{array}$ & $\begin{array}{l}179(7.4) \\
1,196(49.2)\end{array}$ & $\begin{array}{l}66(2.7) \\
992(40.8)\end{array}$ & 2.25 & $1.67,3.01$ & $<0.0001$ \\
\hline ZnT8A & $\begin{array}{l}\text { TPOAb + } \\
\text { TPOAb - }\end{array}$ & $\begin{array}{l}175(7.2) \\
1,418(58.3)\end{array}$ & $\begin{array}{l}70(2.9) \\
770(31.6)\end{array}$ & 1.35 & $1.02,1.82$ & 0.039 \\
\hline ZnT8RA & $\begin{array}{l}\text { TPOAb + } \\
\text { TPOAb - }\end{array}$ & $\begin{array}{l}147(6.0) \\
1,158(47.6)\end{array}$ & $\begin{array}{l}98(4.0) \\
1,030(42.4)\end{array}$ & 1.33 & $1.02,1.74$ & 0.036 \\
\hline IAA & $\begin{array}{l}\text { TPOAb + } \\
\text { TPOAb - }\end{array}$ & $\begin{array}{l}66(2.7) \\
739(30.4)\end{array}$ & $\begin{array}{l}179(7.6) \\
1,451(59.6)\end{array}$ & 0.72 & $0.54,0.97$ & 0.030 \\
\hline GADA & $\begin{array}{l}\text { TGAb + } \\
\text { TGAb - }\end{array}$ & $\begin{array}{l}147(6.0) \\
1,228(50.5)\end{array}$ & $\begin{array}{l}48(2.0) \\
1,010(41.5)\end{array}$ & 2.52 & $1.80,3.52$ & $<0.0001$ \\
\hline ZnT8A & $\begin{array}{l}\text { TGAb }+ \\
\text { TGAb - }\end{array}$ & $\begin{array}{l}143(5.9) \\
1,447(59.5)\end{array}$ & $\begin{array}{l}52(2.1) \\
791(32.5)\end{array}$ & 1.50 & $1.08,2.1$ & 0.015 \\
\hline
\end{tabular}

Results are presented as $n(\%)$ unless stated otherwise

Only islet autoantibody associations showing statistical significance are shown 
Table 2 Association between HLA-DQ genotype ${ }^{a}$ and either TPOAb or TGAb

\begin{tabular}{|c|c|c|c|c|c|c|c|}
\hline \multirow[t]{2}{*}{ HLA-DQ } & \multirow[t]{2}{*}{ Thyroid autoantibody } & \multicolumn{2}{|l|}{ HLA-DQ } & \multirow[t]{2}{*}{ OR } & \multirow[t]{2}{*}{$95 \% \mathrm{CI}$} & \multirow[t]{2}{*}{$p$ value } & \multirow[t]{2}{*}{$p_{\mathrm{c}}$ value } \\
\hline & & Positive & Negative & & & & \\
\hline$D Q 5.1 / 5.1 ; 5.1 / \mathrm{X}^{\mathrm{b}}$ & $\begin{array}{l}\text { TPOAb + } \\
\text { TPOAb - }\end{array}$ & $\begin{array}{l}28(1.2) \\
416(17.0)\end{array}$ & $\begin{array}{l}217(8.9) \\
1,772(72.8)\end{array}$ & 0.55 & $0.37,0.83$ & 0.004 & 0.012 \\
\hline$D Q 8 / 5.1$ & $\begin{array}{l}\text { TPOAb }+ \\
\text { TPOAb - }\end{array}$ & $\begin{array}{l}14(0.57) \\
228(9.3)\end{array}$ & $\begin{array}{l}231(9.5) \\
1,960(80.5)\end{array}$ & 0.52 & $0.30,0.90$ & 0.019 & 0.057 \\
\hline$D Q 5.1 / \mathrm{X}^{\mathrm{c}}$ & $\begin{array}{l}\text { TPOAb }+ \\
\text { TPOAb }-\end{array}$ & $\begin{array}{l}5(0.2) \\
117(4.8)\end{array}$ & $\begin{array}{l}240(9.9) \\
2,071(85.1)\end{array}$ & 0.37 & $0.15,0.91$ & 0.025 & 0.075 \\
\hline$D Q 2 / \mathrm{X}^{\mathrm{b}}$ & $\begin{array}{l}\mathrm{TGAb}+ \\
\mathrm{TGAb}-\end{array}$ & $\begin{array}{l}107(4.4) \\
1,024(42.0)\end{array}$ & $\begin{array}{l}88(3.6) \\
1,214(49.9)\end{array}$ & 1.44 & $1.07,1.93$ & 0.014 & 0.098 \\
\hline$D Q 6.4 / \mathrm{X}^{\mathrm{b}}$ & $\begin{array}{l}\text { TGAb }+ \\
\text { TGAb }-\end{array}$ & $\begin{array}{l}10(0.4) \\
218(9.0)\end{array}$ & $\begin{array}{l}185(7.6) \\
2,020(83.0)\end{array}$ & 0.50 & $0.26,0.96$ & 0.034 & 0.238 \\
\hline$D Q 5.1 / \mathrm{X}^{\mathrm{b}}$ & $\begin{array}{l}\text { TGAb + } \\
\text { TGAb - }\end{array}$ & $\begin{array}{l}22(1.0) \\
418(17.2)\end{array}$ & $\begin{array}{l}173(7.0) \\
1,820(74.8)\end{array}$ & 0.55 & $0.35,0.87$ & 0.010 & 0.07 \\
\hline$D Q 8 / 5.1$ & $\begin{array}{l}\text { TGAb }+ \\
\text { TGAb - }\end{array}$ & $\begin{array}{l}9(0.4) \\
233(9.6)\end{array}$ & $\begin{array}{l}186(7.6) \\
2,005(82.4)\end{array}$ & 0.42 & $0.32,0.83$ & 0.0095 & 0.067 \\
\hline$D Q 5.1 / \mathrm{X}^{\mathrm{b}}$ & $\begin{array}{l}\text { Positive for TPOAb, TGAb or both } \\
\text { Negative for TPOAb, TGAb or both }\end{array}$ & $\begin{array}{l}35(1.4) \\
409(16.8)\end{array}$ & $\begin{array}{l}264(10.9) \\
1,725(70.9)\end{array}$ & 0.56 & $0.39,0.81$ & 0.002 & 0.014 \\
\hline$D Q 8 / 5.1$ & $\begin{array}{l}\text { Positive for TPOAb, TGAb or both } \\
\text { Negative for TPOAb, TGAb or both }\end{array}$ & $\begin{array}{l}17(0.7) \\
225(9.2)\end{array}$ & $\begin{array}{l}282(11.6) \\
1,909(78.5)\end{array}$ & 0.51 & $0.31,0.85$ & 0.0085 & 0.060 \\
\hline
\end{tabular}

Results are presented as $n(\%)$ unless stated otherwise

${ }^{a}$ The following abbreviations are used for the HLA-DQ haplotypes: DQ5.1 is DQA1*01:01-B1*05:1; DQ8 is DQA1*03:01-B1*03:02; DQ2 is $D Q A 1 * 05: 01-B 1 * 02: 01$; and DQ6.4 is DQA $1 * 01: 02-\mathrm{B} 1 * 06: 04$

${ }^{\mathrm{b}} \mathrm{X}$ is any haplotype

${ }^{\mathrm{c}} \mathrm{X}$ is not DQ2 or DQ8

cohort made it possible to confirm the negative association between HLA-DQ5.1 and either TPOAb, TGAb or both, as previously reported in 285 children with type 1 diabetes [13]. As TPOAb and TGAb, considered together, were weakly negatively associated with the $D Q 8 / 5.1$ genotype, it cannot be excluded that $D Q 8$ also contributes to protection from thyroid autoimmunity. Our study therefore indicates that primarily $H L A-D Q 5.1$, but perhaps also $D Q 8$, protects children with type 1 diabetes against developing AITD. These results and the association between AITD and $D Q 2$, as earlier described [24, 25], draw attention to the probable importance of $H L A-D Q$ alleles for the risk of AITD in type 1 diabetes. However, the associations between thyroid autoimmunity and $H L A-D Q$ were weak and did not fully explain the cooccurrence of islet and thyroid autoimmunity.

In this large population-based study of almost all children up to 18 years of age diagnosed with type 1 diabetes in Sweden between May 2005 and October 2009 it was possible to perform a detailed analysis of the associations

Table 3 Association between thyroid autoantibodies and possible clinical thyroid disease based on analyses of TSH and free T4 at onset of type 1 diabetes

\begin{tabular}{|c|c|c|c|c|c|c|}
\hline \multirow[t]{2}{*}{ Clinical thyroid disease } & \multirow{2}{*}{$\begin{array}{l}\text { Thyroid autoantibody: } \\
\text { TPOAb, TGAb or both }\end{array}$} & \multicolumn{2}{|c|}{ Thyroid antibodies } & \multirow[t]{2}{*}{ OR } & \multirow[t]{2}{*}{$95 \% \mathrm{CI}$} & \multirow[t]{2}{*}{$p$ value } \\
\hline & & Positive & Negative & & & \\
\hline Hypothyroid disease $^{a}$ & $\begin{array}{l}+ \\
-\end{array}$ & $\begin{array}{l}6(0.25) \\
293(12.0)\end{array}$ & $\begin{array}{l}1(0.04) \\
2,133(87.7)\end{array}$ & 43.7 & $5.23,364.10$ & $<0.001$ \\
\hline Hyperthyroid disease $^{\mathrm{b}}$ & $\begin{array}{l}+ \\
-\end{array}$ & $\begin{array}{l}5(0.21) \\
294(12.05)\end{array}$ & $\begin{array}{l}1(0.04) \\
2,133(87.7)\end{array}$ & 36.3 & $4.22,311.6$ & $<0.001$ \\
\hline
\end{tabular}

Results are presented as $n(\%)$ unless stated otherwise

${ }^{\mathrm{a}} \mathrm{TSH}>8 \mathrm{mU} / \mathrm{l}, \mathrm{fT} 4<2 \mathrm{pmol} / \mathrm{l}$

${ }^{\mathrm{b}} \mathrm{TSH}<0.01 \mathrm{mU} / \mathrm{l}, \mathrm{fT} 4>22 \mathrm{pmol} / \mathrm{l}$ 
between thyroid disease markers, islet autoantibodies and HLA genotypes. Since all children were analysed for all three variants of ZnT8A at diagnosis, we were able to reveal associations between the three variants of ZnT8A and thyroid autoantibodies in a way that has previously not been described.

A possible weakness to our analysis is that the results were only based upon the sampling at onset of type 1 diabetes. First, it cannot be ruled out that a few children had already been diagnosed and treated for AITD. The frequency of AITD in newly diagnosed type 1 diabetes children therefore remains to be determined. Second, it has not been possible to determine conversion to positive thyroid autoantibodies during followup after diagnosis. Hence, the frequency of AITD in patients with type 1 diabetes was likely to be underestimated.

We conclude that thyroid autoantibodies are common in children diagnosed with type 1 diabetes. Our prevalence of thyroid autoantibodies at clinical onset of type 1 diabetes was similar to findings in some previous studies [26, 27], but in other studies a prevalence as high as $15.8-29 \%$ has been reported. However, in these studies, the patients were tested at follow-up and not at the time of diagnosis [1, 13, 14, 28-30], which may explain the higher prevalence. Furthermore, only few children are diagnosed with AITD at the onset of type 1 diabetes [23, 26, 31], while the risk of AITD increases during follow-up of patients with type 1 diabetes. It has been estimated that 10 $33 \%$ of adult patients with long-term type 1 diabetes have been diagnosed with clinical AITD [29, 32-34] and in patients followed from diagnosis TPOAb predict development of future thyroid disease [35]. It is important to diagnose childhood clinical hypothyroidism due to AITD as it has an impact on growth, intellectual development and metabolic control. Since the prevalence of AITD is higher in individuals with type 1 diabetes, screening may be important both at onset and during follow-up.

As in previous reports, girls and children at older age are more likely to have thyroid autoantibodies $[1,13,26,27,29$, 33]. This correlates with reports involving adults wherein women with type 1 diabetes are more prone to autoimmune thyroiditis than men [34].

We could confirm that GADA positivity was associated with both TPOAb and TGAb in children with type 1 diabetes $[1,23]$. The negative association between TPOAb and IAA can be explained by the young age of those children positive for IAA [6]. Our study is the first to reveal an association between thyroid autoantibodies and ZnT8RWQA as one group in children at diabetes onset. This association can partly be explained by a significant association between TPOAb and ZnT8RA, one of the two most common variants of the ZnT8A [6]. The association between thyroid autoantibodies and autoantibodies against ZnT8A is interesting since the zinc transporter is abundant in the cubical cells lining the thyroid follicle [10]. It would therefore be interesting to find out whether ZnT8A is found in patients with AITD without type 1 diabetes.
The findings of previous studies and our study suggest that HLA genotype may be important for the risk of developing both type 1 diabetes and AITD. An association between AITD and HLA-DR3 [36], HLA-DR4 [24, 37] and $D R B 1^{*} 04-D Q B 1^{*} 03: 01[38]$ has been reported. In addition, $H L A-D R 3$ and $D R 3 / D Q B 1^{*} 03: 02$ has also been reported to contribute to both type 1 diabetes and AITD in a study of families with both diseases, while $D R 4$ was associated with type 1 diabetes but not with AITD [25, 28, 39]. Others have failed to find an association between HLA and TPOAb [1]. Our findings, that DQ5.1 was protective for TPOAb and TGAb, confirm the results of a previous study [13]. Additionally, our finding of a weak association between TGAb and $D Q 2$ in part confirms previously reported associations between AITD and $D Q 2[24,25]$. However, our data were not consistent with an association between AITD and HLA$D Q B 1^{*} 03: 02(D Q 8)[13,24,37]$. The differences in results could partly be explained by the fact that our study was primarily focused on thyroid autoimmunity and not on clinical thyroid disease. It cannot be excluded that there may be differences in genetics between AITD and TPOAb and TGAb, similar to the relation between HLA and GADA and IA-2A on one hand and type 1 diabetes on the other [40]. Taken together, the association between HLA and AITD seem to be weaker than between HLA and type 1 diabetes despite these diseases often occurring coherently.

The high-risk genotype for type 1 diabetes, $D Q 2 / 8$, predominates in children diagnosed under the age of 6 years $[13,37]$. Individuals with thyroid autoantibodies at onset of type 1 diabetes diagnosis are often older and less frequently carry the high-risk $D Q 2 / 8$ genotype. Our finding of an association between $H L A-D Q 2$ and thyroid autoimmunity may explain some of the joint genetic susceptibility and family clustering of type 1 diabetes and AITD [25]. However, other non-HLA genes, as well as environmental factors, may contribute to the covariance of AITD and type 1 diabetes. Future research is needed to reveal these relationships as well as to determine how many of our patients with thyroid autoantibodies at onset of type 1 diabetes will develop AITD during follow-up.

In conclusion, children with type 1 diabetes were more likely to develop thyroid autoantibodies. At risk were girls and children with positive GADA or ZnT8RA. HLA-DQ5.1 including $D Q 8 / 5.1$ seemed to protect against thyroid autoimmunity. However, except for the negative association between $D Q 5.1$ and thyroid autoimmunity, $H L A-D Q$ genotype did not significantly affect the risk of thyroid autoimmunity in childhood type 1 diabetes.

Acknowledgements We thank all the participating families and also I. Hansson, J. Hemmendahl, A. Nilsson, M. Pelkonen, A. Shalouie, I. Wigheden and A. Winqvist at the Clinical Research Center, Lund University, Sweden, for their excellent technical assistance. 
Funding Our research is supported in part by the Swedish Research Council (Grant 14064), Swedish Child Diabetes Foundation, Swedish Diabetes Association, National Institutes of Health (DK26190), SUS Fund, the Knut and Alice Wallenberg Foundation and the Skåne County Council for Research and Development.

Duality of interest The authors declare that there is no duality of interest associated with this manuscript.

Contribution statement $\mathrm{BJ}$ analysed and interpreted the data and wrote the manuscript. CA analysed and interpreted the data and edited the manuscript. AD provided data, designed and updated the database for the BDD study. AC, GF, JL, CM, US and EÖ contributed to the study design and edited the manuscript. SAI, ÅL and HEL designed the study, interpreted the data and contributed to and edited the manuscript. All authors approved the final version to be published.

\section{Appendix}

The following are members of the BDD study group, all of whom are in Sweden. The location of the paediatric clinic is given in parentheses: A. J. Delli (Malmö), B.-O. Samuelsson (Borås), K. Snellman (Eskilstuna), A. Olivecrona (Falun), Å. Stenberg (Gällivare), L. Skogsberg (Gävle), B. Lindblad (Göteborg), G. Forsander (Göteborg), N. Nilsson (Halmstad), J. Neiderud (Helsingborg), T. Torbjörnsdotter (Huddinge) T. Hägg (Hudiksvall), K. Hemmingsson (Härnösand), K. Åkesson (Jönköping), G. Lundström (Kalmar), M. Ljungcrantz (Karlskrona), M. Forssberg (Karlstad), K. Larsson (Kristianstad), C. Gundewall (Kungsbacka), R. Enander (Linköping), U. Samuelsson (Linköping), A. Carlsson (Lund), A. Nilsson (Malmö), H. Elding Larsson (Malmö), S.A. Ivarsson (Malmö), A. Brännström (Luleå), M. Nordwall (Norrköping), L. Hellenberg (Nyköping), E. Lundberg (Skellefteå), H. Tollig (Skövde), B. Björsell (Sollefteå), C. Marcus (Stockholm), E. Örtqvist (Stockholm/KS), I. Kockum (Stockholm), B. Stjernstedt (Sundsvall), N. Wramner (Trollhättan), R. Hanås (Uddevalla), I. Swenne (Uppsala), M. Blomgren (Visby), A. Thåström (Västervik), CG Arvidsson (Västerås), S. Edvardsson (Växjö), B. Jönsson (Ystad), T. Gadd (Ängelholm), J. Åman (Örebro), R. Florell (Örnsköldsvik) and A.-L. Fureman (Östersund).

\section{References}

1. De Block CE, de Leeuw IH, Vertommen JJ et al (2001) Betacell, thyroid, gastric, adrenal and coeliac autoimmunity and HLA-DQ types in type 1 diabetes. Clin Exp Immunol 126:236241

2. Eisenbarth GS (1986) Type I diabetes mellitus. A chronic autoimmune disease. N Engl J Med 314:1360-1368

3. Pearce EN, Farwell AP, Braverman LE (2003) Thyroiditis. N Engl J Med 348:2646-2655
4. Bizzaro N (2007) Autoantibodies as predictors of disease: the clinical and experimental evidence. Autoimmun Rev 6:325-333

5. Gorus FK, Goubert P, Semakula C et al (1997) IA-2autoantibodies complement GAD65-autoantibodies in new-onset IDDM patients and help predict impending diabetes in their siblings. The Belgian Diabetes Registry. Diabetologia 40:95-99

6. Andersson C, Larsson K, Vaziri-Sani F et al (2011) The three ZNT8 autoantibody variants together improve the diagnostic sensitivity of childhood and adolescent type 1 diabetes. Autoimmunity 44:394-405

7. Wenzlau JM, Moua O, Sarkar SA et al (2008) S1C30A8 is a major target of humoral autoimmunity in type 1 diabetes and a predictive marker in prediabetes. Ann N Y Acad Sci 1150:256-259

8. Vaziri-Sani F, Delli AJ, Elding-Larsson H et al (2011) A novel triple mix radiobinding assay for the three ZnT8 (ZnT8-RWQ) autoantibody variants in children with newly diagnosed diabetes. J Immunol Methods 371:25-37

9. Chimienti F, Devergnas S, Favier A, Seve M (2004) Identification and cloning of a beta-cell-specific zinc transporter, ZnT-8, localized into insulin secretory granules. Diabetes 53:2330-2337

10. Murgia C, Devirgiliis C, Mancini E, Donadel G, Zalewski P, Perozzi G (2009) Diabetes-linked zinc transporter ZnT8 is a homodimeric protein expressed by distinct rodent endocrine cell types in the pancreas and other glands. Nutr Metab Cardiovasc Dis 19:431-439

11. Sabbah E, Savola K, Kulmala P et al (1999) Diabetes-associated autoantibodies in relation to clinical characteristics and natural course in children with newly diagnosed type 1 diabetes. The Childhood Diabetes In Finland Study Group. J Clin Endocrinol Metab 84:1534-1539

12. Graham J, Hagopian WA, Kockum I et al (2002) Genetic effects on age-dependent onset and islet cell autoantibody markers in type 1 diabetes. Diabetes 51:1346-1355

13. Sumnik Z, Drevinek P, Snajderova M et al (2003) HLA-DQ polymorphisms modify the risk of thyroid autoimmunity in children with type 1 diabetes mellitus. J Pediatr Endocrinol Metabol 16:851-858

14. Hansen D, Bennedbaek FN, Hansen LK, Hoier-Madsen M, Jacobsen BB, Hegedus L (1999) Thyroid function, morphology and autoimmunity in young patients with insulin-dependent diabetes mellitus. Eur J Endocrinol 140:512-518

15. Delli AJ, Vaziri-Sani F, Lindblad B et al (2012) Zinc transporter 8 autoantibodies and their association with SLC30A8 and HLADQ genes differ between immigrant and Swedish patients with newly diagnosed type 1 diabetes in the Better Diabetes Diagnosis Study. Diabetes 61:2556-2564

16. Lampasona V, Schlosser M, Mueller PW et al (2011) Diabetes antibody standardization program: first proficiency evaluation of assays for autoantibodies to zinc transporter 8. Clin Chem 57:1693-1702

17. Mire-Sluis AR, Gaines Das R, Lernmark A (2000) The World Health Organization International Collaborative Study for islet cell antibodies. Diabetologia 43:1282-1292

18. Schlosser M, Mueller PW, Torn C, Bonifacio E, Bingley PJ (2010) Diabetes Antibody Standardization Program: evaluation of assays for insulin autoantibodies. Diabetologia 53:2611-2620

19. Andersson C, Vaziri-Sani F, Delli A et al (2013) Triple specificity of ZnT8 autoantibodies in relation to HLA and other islet autoantibodies in childhood and adolescent type 1 diabetes. Pediatr Diabetes 14:97-105

20. Kiviniemi M, Hermann R, Nurmi J et al (2007) A high-throughput population screening system for the estimation of genetic risk for type 1 diabetes: an application for the TEDDY (the Environmental Determinants of Diabetes in the Young) study. Diabetes Technol Ther 9:460-472

21. Larsson HE, Lynch K, Lernmark B et al (2005) Diabetesassociated HLA genotypes affect birthweight in the general population. Diabetologia 48:1484-1491 
22. Lynch KF, Lernmark B, Merlo J, Cilio CM, Ivarsson SA, Lernmark A (2008) Cord blood islet autoantibodies and seasonal association with the type 1 diabetes high-risk genotype. J Perinatol 28:211-217

23. Kordonouri O, Charpentier N, Hartmann R (2011) GADA positivity at onset of type 1 diabetes is a risk factor for the development of autoimmune thyroiditis. Pediatr Diabetes 12:31-33

24. Zeitlin AA, Heward JM, Newby PR et al (2008) Analysis of HLA class II genes in Hashimoto's thyroiditis reveals differences compared to Graves' disease. Genes Immun 9:358-363

25. Levin L, Ban Y, Concepcion E, Davies TF, Greenberg DA, Tomer Y (2004) Analysis of HLA genes in families with autoimmune diabetes and thyroiditis. Hum Immunol 65:640-647

26. Piatkowska E, Szalecki M (2011) Autoimmune thyroiditis in children and adolescents with type 1 diabetes. Pediatr Endocrinol Diabetes Metabol 17:173-177

27. Kordonouri O, Deiss D, Danne T, Dorow A, Bassir C, GrutersKieslich A (2002) Predictivity of thyroid autoantibodies for the development of thyroid disorders in children and adolescents with type 1 diabetes. Diabet Med 19:518-521

28. Barker JM, Yu J, Yu L et al (2005) Autoantibody 'subspecificity' in type 1 diabetes: risk for organ-specific autoimmunity clusters in distinct groups. Diabetes Care 28:850-855

29. Kakleas K, Paschali E, Kefalas N et al (2009) Factors for thyroid autoimmunity in children and adolescents with type 1 diabetes mellitus. Ups J Med Sci 114:214-220

30. McKenna MJ, Herskowitz R, Wolfsdorf JI (1990) Screening for thyroid disease in children with IDDM. Diabetes Care 13:801-803

31. Joseph J, Saroha V, Payne H et al (2011) Thyroid function at diagnosis of type I diabetes. Arch Dis Child 96:777-779
32. Perros P, McCrimmon RJ, Shaw G, Frier BM (1995) Frequency of thyroid dysfunction in diabetic patients: value of annual screening. Diabet Med 12:622-627

33. Kordonouri O, Klinghammer A, Lang EB, Gruters-Kieslich A, Grabert M, Holl RW (2002) Thyroid autoimmunity in children and adolescents with type 1 diabetes: a multicenter survey. Diabetes Care 25:1346-1350

34. Umpierrez GE, Latif KA, Murphy MB et al (2003) Thyroid dysfunction in patients with type 1 diabetes: a longitudinal study. Diabetes Care 26:1181-1185

35. Glastras SJ, Craig ME, Verge CF, Chan AK, Cusumano JM, Donaghue KC (2005) The role of autoimmunity at diagnosis of type 1 diabetes in the development of thyroid and celiac disease and microvascular complications. Diabetes Care 28:2170-2175

36. Tandon N, Zhang L, Weetman AP (1991) HLA associations with Hashimoto's thyroiditis. Clin Endocrinol (Oxf) 34:383-386

37. Awa WL, Boehm BO, Kapellen T et al (2010) HLA-DR genotypes influence age at disease onset in children and juveniles with type 1 diabetes mellitus. Eur J Endocrinol 163:97-104

38. Petrone A, Giorgi G, Mesturino CA et al (2001) Association of DRB $1 * 04-\mathrm{DQB} 1 * 0301$ haplotype and lack of association of two polymorphic sites at CTLA-4 gene with Hashimoto's thyroiditis in an Italian population. Thyroid 11:171-175

39. Golden B, Levin L, Ban Y, Concepcion E, Greenberg DA, Tomer Y (2005) Genetic analysis of families with autoimmune diabetes and thyroiditis: evidence for common and unique genes. J Clin Endocrinol Metab 90:4904-4911

40. Howson JM, Stevens H, Smyth DJ et al (2011) Evidence that HLA class I and II associations with type 1 diabetes, autoantibodies to GAD and autoantibodies to IA-2, are distinct. Diabetes 60:2635-2644 